\title{
Promoting Physical Activity and Reducing Sedentary Time Among Tertiary Workers: Position Stand From the French National ONAPS
}

\author{
Pauline M. Genin, Frédéric Dutheil, Benjamin Larras, Yoland Esquirol, Yves Boirie, Angelo Tremblay, \\ Bruno Pereira, Corinne Praznoczy, David Thivel, and Martine Duclos
}

\begin{abstract}
The modernization of our societies has resulted in a steady increase in service industry occupations (tertiarization), which have favored increased sedentary time, while reducing occupational physical activity. In less than 50 years, the United States has increased sedentary professions by about $20 \%$, with a parallel decline in professions requiring physical labor. ${ }^{1}$ At the same time, French workers spend approximately 10 hours per day sitting without active breaks on work days and about 7.6 hours per day sitting on nonworking days. ${ }^{2}$ Due to the amount of time that people spend at work, the workplace is now recognized as an opportune setting for promoting an active lifestyle and for developing strategies to reduce sedentary time. ${ }^{3}$ Although there has been a growing body of literature proposing such strategies over the past 10 years, it is difficult to draw conclusions from this work due to the heterogeneity in research methods and the lack of robust statistical analyses. ${ }^{4,5}$ Moreover, such workplace intervention strategies appear to suffer from high attrition, as well as a lack of proven sustainability. ${ }^{6,7}$ Because there is an urgent need to promote physical activity and reduce sedentary time during work time, the French National Conservatory for Physical Activity and Sedentary Behaviors (ONAPS) recently dedicated its annual congress (January 29-30, 2019 in Vichy, France) to this important public health issue. The congress convened an expert panel comprising scientists, public health specialists, occupational physicians, ergonomists, as well as both workers and their employers to examine strategies for improving workplace health. This commentary summarizes the initial conclusions of this expert panel and details the main findings and recommendations regarding the promotion of physical activity and reduction of sedentary time among tertiary employees.
\end{abstract}

Genin, Larras, Boirie, Tremblay, Pereira, Praznoczy, Thivel, and Duclos are with the National Observatory for Physical Activity and Sedentary Behaviors (ONAPS), Clermont-Ferrand, France. Genin is also with Clermont Auvergne University, Clermont-Ferrand, France. Dutheil is with Occupational Medicine, University Hospital CHU G. Montpied, Clermont-Ferrand, France. Dutheil, Boirie, and Duclos are also with University Clermont 1, UFR Medicine, Clermont-Ferrand, France. Esquirol is with Consultation de pathologie-professionnelle, Hôpital Purpan, Université de Toulouse, Toulouse, France. Tremblay is also with Département de l'éducation Physique, Faculté des Sciences de l'éducation, Université Laval, Québec City, Canada. Pereira is also with Biostatistics Unit (DRCI), ClermontFerrand University Hospital, Clermont-Ferrand, France. Thivel is also with EA 3533, Laboratory of the Metabolic Adaptations to Exercise under Physiological and Pathological Conditions (AME2P), Clermont Auvergne University, ClermontFerrand, France. Duclos is also with the Department of Sport Medicine and Functional Explorations, Clermont-Ferrand University Hospital, G. Montpied Hospital, Clermont-Ferrand, France. Boirie and Duclos are also with INRA, UMR 1019, Clermont-Ferrand, France. Boirie is also with the Department of Human Nutrition, Clermont-Ferrand University Hospital, G. Montpied Hospital, ClermontFerrand, France. Genin (pauline_genin@ $@$ hotmail.com) is corresponding author.

\section{What are the First Steps?}

As mentioned previously, attrition from worksite physical activity programs can reach as high as $50 \% .^{1}$ This high level of dropout has been attributable to the lack of individualization of the intervention in meeting the specific needs of employees. ${ }^{1}$ It appears, however, that the majority of participants in such programs are workers who are already active, and who are looking for alternative ways of exercising. Those workers who do not participate or who dropout are the ones who need the programs the most, due to low levels of physical activity and fitness. ${ }^{1}$ There is also a need to adapt these interventions to the capabilities, needs, and wishes of workers, since a high proportion of attrition has been observed in those who participate initially, but who then perceive their progression toward improvement as low. ${ }^{1}$ Based on these observations, it seems clear that worksite physical activity programs cannot be considered as "one size fits all" and that adapted physical activity interventions must be proposed.

\section{A Joint Initiative Encouraging Off-Site Alternatives}

Recently, Genin et $\mathrm{al}^{2}$ proposed an implementation framework targeted toward the empowerment of worksite interventions. What was clear from this work and the work of the expert panel is that any actions engaged within the workplace have to be jointly designed and implemented by workers and employers. Many intervention strategies that have demonstrated sustainability over time have been workerinitiated with support from the administrative hierarchy. In addition to proposing on-site physical activity interventions, the workplace can also promote off-site opportunities for activities, such as local community recreational centers, gyms, and sports clubs. Indeed, some workers may be willing to try out certain activities within the workplace, but may be hesitant to participate fully with their colleagues and supervisors present. Other workers may prefer to exercise before or after work time, thereby requiring an off-site option. Thus, it seems that worksite physical activity interventions should be considered as part of promotional strategies for local associations, clubs, and gyms that might fit better with the lifestyle of a given worker. As a sign of a company's commitment to the health of its workers, the expert panel recommends that employers encourage financial, temporal, and practical agreements with these off-site settings.

\section{A Combined Approach to Promoting Physical Activity and Reducing Sedentary Time}

It is clear now that not only do tertiary occupations favor low levels of physical activity, they are sedentary by nature and thus contribute 
to a dual public health burden. Also, there is now evidence of an interaction between physical activity level and sedentary time. ${ }^{3,4}$ For example, people who meet the minimum physical activity recommendation (150 min/wk of moderate-intensity activity) but accrue high levels of sedentary time throughout the day have a similar mortality risk as those who are less active but have low sedentary time. Moreover, recent data indicate that some important health indicators (such as body mass index, fat-free mass, muscle strength, or worksite well-being) may not be significantly better in active, compared with inactive tertiary workers, due to their common high levels of sedentary time. ${ }^{5}$ On the other hand, among people with very high levels of physical activity (say, $>35 \mathrm{MET} \cdot \mathrm{h} / \mathrm{wk}$ ), the mortality risk between those who sit $<4$ hours per day and those who sit $>8$ hours per day is similar. ${ }^{4}$ Together these findings indicate the need to jointly promote physical activity and reduce sedentary time. In fact, the new message from public health agencies across the globe is "Move more; Sit less." Although further evidence is needed with regard to the best ways to break up sitting time at work-either by introducing activity breaks, providing active workstations, or by office design 6 - the expert panel encourages their promotion and adoption, along with physical activity incentives (such as the availability of exercise stations [bikes for instance], encouragement for active meetings, etc).

\section{A Need to Consider Compensatory Mechanisms}

There is evidence that structured physical activity programs lead to a reduction in daily volitional activity in order to compensate for the energy cost of the exercise. ${ }^{7,8}$ Also, a growing body of evidence suggests that the cognitive tasks required of tertiary occupations are associated with greater energy intake, especially from energy-dense food, $, 9,10$ and that active workstations (eg, cycling desks) may not be sufficient to overcome such nutritional compensation. ${ }^{11}$ This problem presents another opportunity for companies to enact strategies for increasing spontaneous activity and reducing sitting time. Environmental planning and building design should favor central stairways, landscaped walking paths between buildings, fewer parking spaces, increased accessibility to active transport, and the removal of sugarsweetened beverages and unhealthy snacks from vending machines in the workplace in order to counter these compensatory behaviors.

\section{A Need for Further Scientific Evidence}

Although interest in worksite strategies for promoting physical activity and reducing sitting time have increased steadily over the past 10 years, the literature remains inconsistent due to the lack of controlled trials using appropriate methods and sample sizes. ${ }^{12}$ Both the scientists and practitioners who attended the congress are calling for innovative strategies that combine the disciplines of public health, adapted physical activity professionals (educators specialized in the prescription of physical activities adapted to the individuals' capacities and needs), occupational health, and ergonomics. There seems a clear need to involve practitioners of occupational health and ergonomics in the adaptation of work areas and workstations to avoid unforeseen musculoskeletal injuries, as well as to maintain comfort, alertness, and task productivity. Similarly, designing effective physical activity interventions involves a consideration of the worker's physical capabilities, thereby suggesting the need for individualized programs and for adapted physical activity specialists.
Thus, a combination of various health and movement professionals may be necessary to implement effective strategies.

In conclusion, the ONAPS recommends a multidisciplinary approach to the design, implementation, evaluation, and dissemination of individualized and progressive strategies for promoting physical activity and reducing sitting time among tertiary workers. Moreover, the ONAPS is calling for a clear and official recognition of prolonged, work-related sedentary tasks as a potent occupational hazard. Indeed, given the number of tertiary workers globally, the protection of their health and safety is of substantial public health importance.

\section{References}

1. Genin PM, Pereira B, Thivel D, Duclos M. Employees' adherence to worksite physical activity programs: profiles of compliers versus noncompliers. Work. 2018;60(3):507-510. PubMed ID: 30040776 doi:10.3233/WOR-182745

2. Genin PM, Beaujouan J, Thivel D, Duclos M. Is workplace an appropriate setting for the promotion of physical activity? A new framework for worksite interventions among employees. Work. 2019;62(3): 421-426. PubMed ID: 30856142 doi:10.3233/WOR-192873

3. Leon-Munoz LM, Martinez-Gomez D, Balboa-Castillo T, LopezGarcia E, Guallar-Castillon P, Rodriguez-Artalejo F. Continued sedentariness, change in sitting time, and mortality in older adults. Med Sci Sports Exerc. 2013;45(8):1501-1507. PubMed ID: 23439420 doi:10.1249/MSS.0b013e3182897e87

4. Ekelund U, Steene-Johannessen J, Brown WJ, et al. Does physical activity attenuate, or even eliminate, the detrimental association of sitting time with mortality? A harmonised meta-analysis of data from more than 1 million men and women. Lancet. 2016;388(10051):13021310. PubMed ID: 27475271 doi:10.1016/S0140-6736(16)30370-1

5. Genin PM, Dessenne P, Finaud J, Pereira B, Thivel D, Duclos M. Effect of work-related sedentary time on overall health profile in active vs. inactive office workers. Front Public Health. 2018;6:279. PubMed ID: 30327763 doi:10.3389/fpubh.2018.00279

6. Thivel D, Tremblay A, Genin PM, Panahi S, Riviere D, Duclos M. Physical activity, inactivity, and sedentary behaviors: definitions and implications in occupational health. Front Public Health. 2018;6:288. PubMed ID: 30345266 doi:10.3389/fpubh.2018.00288

7. Rowland TW. The biological basis of physical activity. Med Sci Sports Exerc. 1998;30(3):392-399. PubMed ID: 9526885 doi:10. 1097/00005768-199803000-00009

8. Thivel D, Aucouturier J, Metz L, Morio B, Duche P. Is there spontaneous energy expenditure compensation in response to intensive exercise in obese youth? Pediatr Obes. 2014;9(2):147-154. PubMed ID: 23447495 doi:10.1111/j.2047-6310.2013.00148.x

9. Chaput JP, Tremblay A. Acute effects of knowledge-based work on feeding behavior and energy intake. Physiol Behav. 2007;90(1):66-72. PubMed ID: 17023010 doi:10.1016/j.physbeh.2006.08.030

10. Chaput JP, Drapeau V, Poirier P, Teasdale N, Tremblay A. Glycemic instability and spontaneous energy intake: association with knowledge-based work. Psychosom Med. 2008;70(7):797-804. PubMed ID: 18725427 doi:10.1097/PSY.0b013e31818426fa

11. Thivel D, Genin PM, Fillon A, et al. Bureau-vélo: stratégie efficace de lutte contre la sédentarité et ses effets aux travail? Second colloque de l'ONAPS Oral Communication. Vichy, France; 2019.

12. Johnson S, Regnaux JP, Marck A, Berthelot G, Ungureanu J, Toussaint JF. Understanding how outcomes are measured in workplace physical activity interventions: a scoping review. BMC Public Health. 2018;18(1):1064. PubMed ID: 30144823 doi:10.1186/ s12889-018-5980-x 